Acta Cryst. (2002). A58 (Supplement), C330

CRYSTAL STRUCTURE, MAGNETIC PROPERTIES AND HYBRID DF/HF CALCULATIONS OF NITRONYL NITROXIDE RADICALS

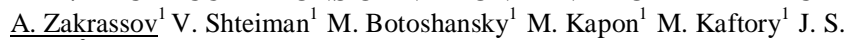
Miller $^{2}$

${ }^{1}$ Department of Chemistry and Lise Meitner Minerva Center for the Computational and Quantum Chemistry. Technion - Israel Institute of Technology Technion City HAIFA 32000 ISRAEL ${ }^{2}$ Department of Chemistry, university of Utah, USA

We are aiming to design and synthesize ferromagnetically coupled organic radicals. According to this goal, crystal structure, magnetic properties and hybrid DF/HF (Density Functional/Hartree-Fock) Gaussian 98 calculations of nitronyl nitroxide radicals containing different substituents at the 2-position of the imidazole ring are reported. (I) crystallizes in two polymorphic forms. The $\alpha$ form is monoclinic, with four molecules in the asymmetric unit. The $\beta$ form is monoclinic, with one molecule in the asymmetric unit. In the $\alpha$ form there are three structurally different dimers, while only one dimer presents in the $\beta$ form. (II) crystallizes in orthorhombic space group. The magnetic measurements have shown that both $\alpha$ and $\beta$ polymorphs of (I) exhibit antiferromagnetic coupling. The best fitting with the experimental data were obtained using Bleany-Bowers model for the $\alpha$ phase $(\mathrm{J}=-15.0 \mathrm{~K})$ and dimer model $(\mathrm{J}=-11.2 \mathrm{~K})(1)$ for the $\beta$ phase. Hybrid DF/HF Gaussian 98 calculations of both single molecules and dimers are in a good agreement with the experimental geometries. The calculated isotropic hyperfine coupling constants and spin densities of nitrogen are very close to the experimental data obtained by ESR measurements for these compounds and polarized neutron diffraction studies of similar nitronyl nitroxide radicals. The $\mathrm{J}$ value for both $\alpha$ and $\beta$ polymorphs of (I) has been calculated to be $-110.6 \mathrm{~K}$. The crystal structures were previously determined but never been published in details (1).

1. Y. Hosokoshi, M. Tamura, K. Nozawa, S. Suzuki, M. Kinishita, H. Sawa, R. Kato. Synthetic Metals. 1995(71), 1795-1796.<smiles>CC1(O)C=C([Hg])N([O-])C1(C)C</smiles><smiles>CC1=C([O-])N([O-])C(C)(C)C1(C)C</smiles>

Keywords: MAGNETIC PROPERTIES ORGANIC RADICALS POLYMORPHISM

Acta Cryst. (2002). A58 (Supplement), C330

\section{DENDRIMERS WITH NIOBIUM IMIDO COMPLEXES. MONONUCLEAR MODELS}

M.P. Gomez-Sal J.M. Benito E. de Jesus F.J. de la Mata J.C. Flores R. Gomez Universidad De Alcala Departamento Quimica Inorganica Campus Universitario ALCALA DE HENARES 28871-MADRID 28871 SPAIN

An increasing number of reports have been published on the incorporation of transition metals at the core, branches, or periphery of dendrimers. ${ }^{1}$ Applications of these macromolecular systems in areas such as catalysis ${ }^{2}$ are being widely studied. However, little attention has been paid to dendrimers containing early-transition metals. This drawback led us to focus our research on the synthesis of dendrimers containing group 4 and 5 complexes at their periphery or at their focal point. ${ }^{3}$ Recently, ${ }^{4}$ we have shown that carbosilane dendrimers functionalized with aniline groups might support early-transition metal complexes at their periphery through imido bonds. Imido ligands are exceptionally suited for the stabilization of high-valent metal complexes due to their strong $\pi$-donor abilities. Here, we present the synthesis and structural studies of new niobium(V) imido dendrimers obtained by reaction of metal chlorides with the N,N-bis(trimethylsilyl)aniline end-groups of oxygen-free dendrimers. Previous synthetical and X-ray diffraction structural studies on mononuclear models $\left[\left(\eta^{5}-\mathrm{C}_{5} \mathrm{H}_{4} \mathrm{SiMe}_{3}\right) \mathrm{Nb}\left(\mathrm{N}-\mathrm{C}_{6} \mathrm{H}_{4}-4-\mathrm{SiMe}_{3}\right) \mathrm{Cl}_{2}\right]$ and $[\mathrm{Nb}(\mathrm{N}-$ $\left.\left.\mathrm{C}_{6} \mathrm{H}_{4}-4-\mathrm{SiMe}_{3}\right) \mathrm{Cl}_{3}(\mathrm{NCMe})\right]$ are in addition presented.

\section{References}

(1)Newkome, G. R..; He, E.; Moorefield, C.N. Chem. Rev. 1999, 99, 1689.

(2) Oosterom, G. E.; Reek, J. N. H.; Kamer, P. C. J.; van Leeuwen, P. W. N. M. Angew. Chem. Int. Ed. 2001, 40, 1828.

(3) Arévalo, S.; de Jesús, E.; de la Mata, F. J.; Flores, J. C.; Gómez R. Organometallics 2001, 20, 2583.

(4) Benito, J. M.; Arévalo, S.; de Jesús, E.; de la Mata, F. J.; Flores, J. C.; Gómez R. J. Organomet. Chem. 2000, 610, 42.

Keywords: DENDRIMERS,ORGANOMETALLICSCOMPLEXES,NIOBIUM
Acta Cryst. (2002). A58 (Supplement), C330

\section{WATER CLUSTERS IN ORGANIC MOLECULAR CRYSTALS IN} THE CSD

L. Infantes S. Motherwell Cambridge Crystallographic Data Centre 12 Union Road CAMBRIDGE CB2 $1 \mathrm{EZ} \mathrm{UK}$

Water clusters have been extensively studied both theoretically and experimentally. However, there are no analyses of the different hydrogenbonded $\left(\mathrm{H}_{2} \mathrm{O}\right)_{n}$ clusters present in the solid state. The presence of water molecules in the structure can play an important role in stabilising some supramolecular species since the number of hydrogen bond acceptors and donors can differ significantly from those of the anhydrous compounds. In the present work we have examined more than 1500 hydrated structures retrieved from the CSD. In the first step of our analysis we removed everything other than the water molecules and selected only those structures where the water molecules are $\mathrm{H}$-bonded together, forming patterns either of infinite $1 \mathrm{D}$ chains, 2D sheets, 3D networks, or cyclic motifs. The most common motifs are: (a) for isolated clusters (dimension zero) the tetramer motif (b) for 1-dimensional chains and ladders the pattern using 4 molecules to make the repeat in a linear chain (c) for 2-dimensional sheets the motifs forming 4, 5 and 6 membered rings. For 3-dimensional networks there are no predominant patterns. In the case of 1-dimensional ladders the motif is formed by linked rings sharing edges or nodes. The most predominant are a pattern with linked 5-membered rings sharing one edge, and another pattern with linked alternate 4-6 membered rings sharing one edge.

Keywords: WATER CLUSTERS H-BONDING

\section{Acta Cryst. (2002). A58 (Supplement), C330 \\ SYNTHETIC STUDIES OF HYDROGEN BONDING IN CRYSTAL STRUCTURES OF METAL CHLORIDE COMPLEXES}

A. Angeloni A.G. Orpen

University of Bristol School of Chemistry Cantocks Close BRISTOL BS8 1TS UK

The design of crystalline phases of molecular solids is a goal which is attracting rapidly increasing attention from workers in the field of molecular electronics, pigment chemistry, crystal growth and many others. The objective of this type of research is to allow engineering of properties of the assembly of molecules, properties which are dependent on both the nature of the individual molecules and on the way they aggregate in the crystal. To understand the latter (and eventually control it) we need to study the interactions between molecules, the non-covalent links that hold the crystal structure together. These extra-molecular interactions lead to the crystal structure in somewhat the same way that covalent bonds lead to molecular structure. We have shown that chloride ligands are highly effective as hydrogen bond acceptors and have a pronounced angular preference for $\mathrm{M}-\mathrm{Cl}{ }^{\cdots} \mathrm{H}$ at ca. $100^{\circ}$. Use of an $\mathrm{H}_{-} \mathrm{N}^{+}$organic hydrogen bond donor based on 4,4-bipyridine gave 1-D and 2-D motifs incorporating an $\mathrm{MCl}_{2}$ ' $\mathrm{HN}^{+}$supramolecular synthon. Here we report studies of the influence of the shape, topology, and functionality of the organic component on the crystal structures formed with perhalometallate anions. While 4,4-bipyridinium affords a ribbon structure with $\left[\mathrm{PtCl}_{4}\right]^{2-}$, the use of species such as diprotonated trans-1,2-di(4-pyridyl)ethene (see below), 1,2di(4-pyridyl)ethane or 4,4-bipiperidine and supramolecular analogues affords variations on this structural motif. The degree of variation and control over the crystal structures afforded by the organic component will be reported.

Keywords: SYNTHON, HYDROGEN BOND, CRYSTAL ENGINEERING 